\title{
A Dinâmica da Agricultura Francesa: inovação, transformação e identidade social
}

\author{
Angélica Massuquetti $i^{1,2}$
}

\begin{abstract}
Resumo: Este artigo investiga o processo de modernização agrícola na França com base na interpretação de economistas, sociólogos e cientistas políticos, envolvendo especialmente o debate da economia e da sociologia rural contemporâneas. O objetivo é compreender a sua dinâmica pelo cruzamento entre diferentes áreas do conhecimento, visando refletir acerca de um modelo interpretativo para a análise da especificidade do processo brasileiro de modernização agrícola. O mundo rural não se transformou unicamente no âmbito econômico, por meio da adoção de inovações e de novas inserções no mercado, mas houve também a construção de novas identidades políticas e sociais no campo.
\end{abstract}

Palavras-chave: modernização, agricultura, identidade social.

Abstract: This paper examines the French agricultural modernization process based on the evaluation of economists, social and political scientists, involving especially the debate of the contemporary social science and rural economics. The objective is to understand its dynamics by the relationship between different areas of knowledge, aiming at setting up an interpretative model to analyse the specific Brazilian agricultural modernization process. The rural area has not been transformed uniquely on economic grounds, by adopting innovations and new market approaches, but there was also a set up of new political and social identities on rural areas.

Key-words: modernization, agriculture, social identity.

Classificação JEL: Q16, Q18, Q19.

1 Professora e Pesquisadora do Programa de Pós-Graduação em Economia (PPGE) da Universidade do Vale do Rio dos Sinos (UNISINOS). E-mail: angelicam@unisinos.br

2 A autora agradece as contribuições de Afrânio Raul Garcia Jr. (Centre de Recherches sur le Brésil Contemporain - CRBC / École des Hautes Etudes en Sciences Sociales - EHESS) e o apoio financeiro da CAPES (Programa de Doutorado no País com Estágio no Exterior - PDEE). 


\section{Introdução}

Oadvento da modernização agrícola compõe um fenômeno complexo, que deve ser abordado por uma perspectiva sustentada em múltiplas dimensões. À alteração das técnicas de produção e às novas inserções mercadológicas, invariavelmente, correspondem reacomodações no terreno das relações sociais no meio rural e, mesmo, na esfera das representações políticas desse setor. Logo, compreender a modernização agrícola implica traçar um horizonte multidisciplinar, cujas interações entre economia e sociedade estejam longe dos determinismos causalistas.

No mundo inteiro, a modernização agrícola, realizada sob a égide da lógica da produção industrial, tornou tênue os contornos do chamado "mundo rural" - sua ética e seu tempo, suas tradições e procedimentos são abruptamente transformados e engendram outras tantas mudanças que se reatroalimentam. Enquanto surgem novos atores, velhas figuras não encontram mais a chance de alguma linha de continuidade. Mercados e concorrências de distâncias longínquas exercem pressões que geram incertezas. Volumes de produção são incrementados a expoentes expressivos, suscitando novas questões de logística e introduzindo-se atores até então desconhecidos na cadeia produtiva-circulatória. O campo deixa de produzir para a cidade e passa a abastecer o mundo. A identidade social dos agricultores é abalada quando sua estima é posta na escala dos valores urbanos. $\mathrm{O}$ rural é articulado intimamente ao urbano, ao industrial e ao internacional.

Nesse curso, são urgentes pesquisas a respeito da modernização agrícola que se debrucem tanto sobre as similitudes como sobre as especificidades desse processo, ocorrido em tantos países. A presente investigação sobre o processo de modernização agrícola francesa tem como objetivo imediato compreender a sua dinâmica específica pelo cruzamento entre os debates surgidos nas interpretações de economistas, sociólogos e cientistas políticos, envolvendo especialmente o debate da economia e da sociologia rural contemporâneas. Relativamente a cada um desses domínios de análise e cruzamentos, as obras referenciais pesquisadas neste artigo e suas respectivas abordagens foram as seguintes:

1. Em La grande transformation de l'agriculture, obra organizada por Gilles Allaire e Robert Boyer, são utilizados os aportes convencionalistas e regulacionistas para analisar as novas especificidades de organização do setor estimuladas pelo progresso da indústria;

2. Em La fin des paysans, Henri Mendras discute - a partir de uma perspectiva sociológica fortemente orientada por constante debate com a visão econômica - a lógica de desaparecimento da figura tradicional do camponês entre os trabalhadores da sociedade rural da França;

3. Michel Gervais, Marcel Jollivet e Yves Tavernier, em La fin de la France paysanne: de 1914 à nos jours, analisam o modo como o setor agrícola francês repentinamente mudou ao se inserir no processo de modernização e no circuito internacional de produção para a exportação de mercadorias a partir dos anos 50; 
4. A análise da organização política dos camponeses franceses é feita na obra dirigida por Yves Tavernier, Michel Gervais e Claude Servolin, L'univers politique des paysans dans la France contemporaine, produzida a partir de um colóquio em 1970;

5. Em Le bal des célibataires, Pierre Bourdieu analisa a crise da sociedade camponesa tradicional da França, entre os anos 60 e 70, através do estudo das mudanças das regras de celibato dos filhos mais velhos e seu reflexo no sistema de repartição e legação das pequenas propriedades rurais;

6. Para Patrick Champagne, em L'héritage refusé, a transformação do mundo rural ultrapassa o âmbito exclusivamente econômico. Uma forte crise de identidade social relativa à figura do camponês e ao valor (positivo) de suas ocupações também se sucede. Centrando sua análise nas décadas de 70 e 80, o autor mostra que a gradativa queda na reprodução dos atores do mundo rural não se devia simplesmente à evolução técnica da produção, mas também aos aspectos socioculturais que exprimiam já uma verdadeira dominação simbólica do modo de vida urbano;

7. Patrick Campagne e Sylvain Maresca, em De la succession familiale a l'installation professionnelle, também analisam o processo de reprodução social no campo francês, investigando os problemas da sucessão e da instalação;

8. Sylvain Maresca observa os representantes dos camponeses e o processo de construção da identidade desse grupo em Les dirigeants paysans;

9. Por fim, Rose-Marie Lagrave, em Celles de la terre: agricultrice - l'invention politique d'un métier, estuda os reflexos da modernização no processo de reconhecimento profissional da mulher no exercício das atividades ligadas ao mundo agrícola, bem como sua participação no fomento à socialização urbana, especialmente ligada à esfera sindical.

Como segundo objetivo, imediato e a ser desenvolvido ulteriormente, buscarse-á refletir acerca de um modelo interpretativo ensaiado para o estabelecimento de campos de análise e zonas de cruzamento que permitam a construção de um paralelo com a especificidade do processo brasileiro de modernização agrícola. Nesse sentido, pretende-se o aperfeiçoamento de um modelo explicativo capaz de congregar diversos domínios que, na sua especificidade, possam ser também percebidos e mensurados no contexto brasileiro.

\section{Múltiplas interpretações acerca da modernização agrícola}

\subsection{Transformações agrícolas e mercado}

Em La grande transformation de l'agriculture, organizada por Gilles Allaire e Robert Boyer, os aportes convencionalistas e regulacionistas foram utilizados para estudar as transformações agrícolas. A forma de organização do setor e 
as ligações deste com o progresso estimulado pela indústria foram discutidas na obra, principalmente no âmbito dos impactos ocasionados pelo processo de integração cada vez maior dos países europeus nas últimas décadas - em outras palavras, num novo contexto de mercado para os produtos agrícolas: concorrência de preços, qualidade e mudança no padrão de consumo.

A partir dos anos 80, passou-se a estudar, além do seu processo de funcionamento, a maneira como os modos de gestão da agricultura e da indústria agroalimentar se transformavam. Outro aspecto foi a própria renovação das teorias empregadas nesses estudos, preocupadas com problemas mais variados do que aqueles dos anos 60:

C'est ainsi le cas de la nouvelle théorie microéconomique qui cherche à incorporer les problèmes d'information, de qualité, ou encore les raisons de la hiérarchie des firmes, leur forme d'organisation interne et leurs relations avec l'extérieur. Il en est de même concernant les théories macroéconomiques qui redécouvrent l'endogénéité du changement technique, le rôle de la concurrence imparfaite et de la différenciation des biens, le tout dans le contexte d'économies beaucoup plus ouvertes que par le passé (ALLAIRE e BOYER, 1995, p. 9).

Essas pesquisas contribuíram para a renovação das análises da economia rural. Isso porque o interesse passou a ser encontrar a solução para a crise do regime de acumulação fordista e, consequentemente, para o entendimento das lógicas de funcionamento e das condições de transformação das regras institucionais que suportavam as regulações setoriais ou locais.

A análise do setor agroalimentar compreendeu as convenções de qualidade, ou seja, a qualificação dos bens produzidos e comercializados, marcas, etiquetas e normas, bem como a qualificação dos trabalhadores envolvidos no processo de fabricação. Em seguida, a variedade de formas de coordenação se readaptou no interior dos desiguais desempenhos setoriais. Esses estudos, em grande parte sobre os anos 70 e 80 , testemunharam as transformações nos mecanismos de reconhecimento da qualidade oriundas da dinâmica interna do setor agrícola e alimentar e da desestabilização do regime de crescimento internacional. Por fim, a partir da abordagem da regulação, estudou-se a importância da agricultura dentro do modo de crescimento do período após a Segunda Guerra Mundial.

$\mathrm{O}$ crescimento agrícola do pós-guerra estava inserido num regime de acumulação intensiva baseado no consumo de massa. Os regulacionistas ressaltaram as formas institucionais que asseguravam a estabilidade desse regime de crescimento (relação salarial e formas de troca):

Cette période correspond à une accélération simultanée des deux tendances historiques de l'agriculture (régression du volume de travail et hausse de la productivité). S'instaure un régime de production agricole de masse (tendance vers des exploitations et bassins de production spécialisés) et d'accumulation 
intensive. La croissance de la production agricole, tirée par l'accroissement de la demande intérieure et permise par une hausse et une transformation des consommations productives de l'agriculture, l'exode agricole et son corollaire l'urbanisation, sont autant de dynamiques qui contribuent à l'autocentrage du développement fordiste.

[...]

Enfin, la croissance agricole est soutenue par une certaine protection des prix qui permet à l'agriculture de conquérir son marché intérieur et de développer as consommation productive. La demande finale résulte de l'accroissement de la population, de la réduction de l'autoproduction (urbanisation) et d'une relative protection du marché intérieur (ALLAIRE e BOYER, 1995, p. 346-347).

A Política Agrícola Comum (PAC) assegurou a difusão do modelo fordista de industrialização do setor agrícola através das suas políticas. Houve também o desenvolvimento intensivo das indústrias a montante e a jusante, com as indústrias agroalimentares tendo papel importante na adaptação da alimentação ao novo modo de vida, na evolução da agricultura e no comércio mundial.

Esse regime de acumulação entrou em crise pelas pressões comerciais. As convenções industriais e os esquemas de intensificação foram desestabilizados, assistindo-se a uma recombinação da organização produtiva sob uma forma mais flexível e via convenções domésticas. As grandes teses que estavam em debate nos anos 70 na economia rural - agricultores percebidos como pequenos produtores negociantes que não concretizavam o lucro ou explorados, a exemplo dos proletários - tiveram poder explicativo, particularmente no que concerne à organização dos sistemas de produção característicos do crescimento agrícola do fordismo. Mas outras questões passaram a ser analisadas, demandando novas abordagens.

\subsection{Inovações, transformações e desenvolvimento do capitalismo no campo}

Em La fin des paysans, Henri Mendras discutiu no final dos anos 60 - a partir da perspectiva sociológica, mas num debate constante com a visão econômica como a lógica e a atitude coerente da sociedade camponesa tradicional francesa sofreram com as mudanças conduzidas pelas inovações. Essa relação entre a inovação e a mudança possibilitava compreender a desordem no sistema econômico, social e moral da sociedade tradicional. $\mathrm{O}$ autor analisou também as reações e as atitudes dos agricultores quando foram colocados em confronto com os mecanismos econômicos, sociais e políticos da sociedade moderna.

A modernização agrícola iniciada na primeira parte do século XX transformou o setor, provocando a própria "industrialização" da agricultura e o desaparecimento do camponês, considerado no contexto da sociedade tradicional: 
Les techniques nouvelles sortent directement des recherches de laboratoire et non des lents tatônnements d'agriculteurs progressistes. Toute la production agricole est commandée par les goûts des consommateurs et l'évolution des marchés. Au même titre que les autres secteurs de production, l'agriculture doit se soumettre au rythme de changement technique et économique de la société industrielle (MENDRAS, 1992, p. 22).

Com a passagem da lógica camponesa para a racionalidade econômica na administração da atividade agrícola, percebeu-se a transformação do camponês em produtor rural. Enquanto o interesse dos economistas, segundo o autor, recaía sobre o grande produtor, em razão da sua participação na produção total, os sociólogos eram atraídos pelo produtor médio, comum, que tentava conciliar a sua rotina às exigências econômicas e técnicas.

Essas inovações eram determinadas externamente, visto que o camponês tradicional não colocava em questão a "tradição", a forma de viver e de trabalhar:

1. o conhecimento sobre como cultivar a terra era herdado da geração precedente e formado pelos longos anos de aprendizagem;

2. o tempo considerado na atividade era aquele estabelecido pela natureza; e

3. não existia separação entre produção e consumo, entre vida econômica e vida familiar, tampouco ocorria a divisão do trabalho - família e exploração eram idênticas.

A necessidade de uma assessoria técnica, a racionalidade da utilização do tempo, a divisão do trabalho, a produção voltada para o mercado, a separação entre produtor e chefe de família, entre outros, eram alguns aspectos da imposição de especialização da atividade, o que provocou uma transformação das estruturas econômicas e familiares. Não era possível compreender esse novo cenário da agricultura a partir da simples análise da função e da posição, pelo lado dos sociólogos, ou pela lógica da produção na concepção dos economistas, pois

L'exploitant n'est ni un patron ni un salarié puisqu'il est les deux; son entreprise qui paraît le prototype de la firme dans un système concurrentiel n'a ni une unité interne ni une autonomie externe suffisante pour être analysée par l'économiste et le sociologue comme un agent économique individualisé: la confusion de l'entreprise et de la famille interdit à la logique économique de présider à la politique de production; l'émiettement du pouvoir de décision au niveau du travailleur de base rend périlleux tout effort d'orientation de la production (MENDRAS, 1992, p. 145).

O camponês francês contemporâneo encontrava-se submerso nas rápidas transformações técnicas e econômicas e enfrentava, simultaneamente, duas lógicas contraditórias. Enquanto alguns permaneciam ligados ao sistema tradicional, outros, principalmente os jovens formados nos movimentos de ação católica, participavam do jogo econômico moderno: 
Dans des sessions et des congrès, ils apprennent à devenir de véritables entrepreneurs et à transformer la gestion de la ferme familiale jusqu'à en faire, croint-ils, une véritable entreprise: une comptabilité précise leur permet de faire des investissements pour augmenter leur profit en suivant de près la conjoncture économique et l'évolution des marchés (MENDRAS, 1992, p. 195-196).

Os economistas rurais, segundo o autor, explicavam esse processo a partir da noção de racionalidade do comportamento econômico. Qualquer atitude diferente daquela adotada pelos agricultores modernos seria irracional. Todavia, o autor enfatizou que existia uma racionalidade no comportamento tradicional dentro das unidades tradicionais e que eram essas duas racionalidades que estavam em conflito.

Os estudos sociológicos americanos focavam o comportamento e a atitude dos agricultores em relação ao processo de mudança a partir de uma abordagem psicossociológica. O objeto de análise era o "bom agricultor": suas qualidades, seus defeitos, sua posição e seu papel social. Esse agricultor estaria conformado à racionalidade econômica, ao contrário do "mau agricultor", que seria incoerente e irracional. Já os estudos europeus privilegiavam a importância da situação familiar e do sistema de valores na análise do agricultor tradicional e do agricultor progressista.

O agricultor tradicional também adotava melhorias na sua atividade. Estas, contudo, estavam relacionadas ao aumento do capital - compra de terras, de material e de animais - e não alteravam o sistema tradicional. Já a via progressista pressupunha uma mudança no sistema de produção e de gestão da atividade. Ela podia conduzir às mesmas melhorias que a outra, mas estas estavam integradas a uma política de gestão e de mercado. Os produtores agrícolas, com o avanço do processo de modernização, acabaram se tornando um grupo profissional semelhante a outros.

Duas décadas após a publicação de La fin de paysans, Henri Mendras confirmava a sua hipótese sobre o fim da sociedade camponesa na França e defendia uma política de desenvolvimento rural. Os agricultores continuavam alimentando a população com a sua produção, e a sociedade rural tinha um renascimento excelente, mas não existia mais o camponês. $\mathrm{O}$ autor alertou para as transformações que mais profundamente revolucionaram o mundo rural:

1. os agricultores não eram mais majoritários no meio rural;

2. ao contrário do que era em outra época, existia a separação entre a família e a exploração;

3. surgiram novas formas de pluriatividade; e

4. houve a ampliação das instituições de representação dos agricultores.

Michel Gervais, Marcel Jollivet e Yves Tavernier, em La fin de la France paysanne: de 1914 à nos jours, afirmaram que o setor agrícola francês mudou repentinamente no contexto do circuito de produção e de troca de mercadorias a partir dos 
anos 50. Essa evolução agrícola e rural estava relacionada às transformações da economia e da sociedade no país e no resto do mundo. Mesmo com as diferenças entre as estruturas de produção agrícola e industrial, as pressões econômicas, sociais e políticas eram as mesmas. Significa dizer que a evolução da indústria e da agricultura estava submetida à necessidade do desenvolvimento do capitalismo francês, levando em consideração as particularidades de cada ramo. Assim, era importante distinguir o papel da agricultura a partir das modificações estruturais da economia francesa e do seu lugar no cenário internacional. O novo panorama era constituído por uma economia mundial dominada por um capitalismo cuja estrutura se transformou e cujo centro passou progressivamente da Europa para os Estados Unidos.

Entretanto, não se podia explicar esse movimento progressivo de modernização do setor agrícola a partir da oposição cidade/campo. Pelo contrário, as dissensões entre a cidade e o campo tinham responsabilidades recíprocas porque eram resultantes da intensificação da divisão do trabalho social provocada pelo desenvolvimento do capitalismo. As mesmas exigências do sistema econômico e social eram indispensáveis para ambos. Não existia um nível de autonomia da agricultura e do mundo rural em relação à sociedade global. A evolução de um e de outro estava ligada à própria evolução do sistema, dos mecanismos de extensão e de transformação interna do capitalismo. Isso só foi possível pelas transformações internas das famílias, dos vilarejos, das representações coletivas camponesas e dos equilíbrios políticos durante o período precedente.

Se as exigências do capitalismo provocaram tais mudanças econômicas, sociais e políticas, estas, inversamente, só ocorreram segundo as circunstâncias permitidas pelas transformações sociais já realizadas, desejadas e impostas pelos atores sociais. As modificações sociais e os problemas políticos não eram apenas consequências das transformações econômicas. Outros aspectos como as especificidades das estruturas agrárias, das explorações agrícolas, da família; as relações sociais no vilarejo; as particularidades das organizações profissionais; a política estatal, entre outros, também colaboravam na definição de um determinado momento histórico. Isto é, a economia, a política e o social tomavam parte do mesmo movimento histórico, provocavam influências recíprocas e também constituíam esse movimento. Todavia, esse processo extraiu seu sentido e suas regras do sistema econômico.

O desenvolvimento do capitalismo acelerou a submissão da produção, do trabalho e do modo de vida dos agricultores às leis do mercado e, principalmente, da mercadoria. É importante compreender como isso aconteceu e explicar como a penetração do universo da mercadoria ocorreu nos diversos aspectos da vida rural, da produção e das políticas agrícolas, bem como no contexto da vida cotidiana dos agricultores, da família, do vilarejo, das relações no espaço das organizações profissionais e das alianças políticas em relação ao Estado.

No período entre as duas grandes guerras, presenciaram-se as transformações no meio rural, que haviam sido indicadas como necessárias durante a Primeira 
Guerra Mundial. Ou seja, a necessidade de uma nova ordem geral dos métodos antigos, incapazes de responder às exigências do país. Foram constatados o desenvolvimento do aparelho industrial e o crescente papel do Estado na articulação do aumento da produtividade do trabalho, na transformação das técnicas de produção, na utilização de máquinas, equipamentos, fertilizantes e produtos químicos, no desenvolvimento do sistema de crédito e de cooperação, no aumento das indústrias de transformação de produtos agrícolas e na integração da agricultura no sistema econômico. O resultado foi o crescimento da produção nacional e a participação do país no grupo dos grandes exportadores de produtos agrícolas. Assim, dentro da lógica do desenvolvimento econômico nacional, foi necessário integrar a agricultura ao resto da economia para melhorar a produtividade do trabalho, de tal forma que esse ramo de produção não impedisse o crescimento do conjunto e também se tornasse uma fonte favorável para a acumulação global de capital.

A transformação técnica ocorrida na agricultura deu nova forma aos métodos, ao ritmo do trabalho e aos relacionamentos com as outras atividades produtivas, reduzindo sua autonomia. No entanto, para os trabalhadores agrícolas assalariados, a industrialização da agricultura não assegurou o alinhamento das condições de trabalho com aquelas dos operários da indústria. Na verdade, os baixos salários estavam presentes na vida dos trabalhadores do meio rural. Além disso, esse processo também provocou a redução da população agrícola e, ao contrário do que se supunha, a unidade de produção familiar conseguiu se adaptar às exigências do sistema social, utilizando os meios de produção colocados à disposição pela indústria.

Uma nova etapa no desenvolvimento das forças produtivas foi possível com as mudanças das estruturas políticas a partir do final dos anos 50. Os resultados foram percebidos nas organizações sindicais, no advento de uma linguagem nova - com o mito da unidade dos chefes de explorações substituindo aquele da unidade do mundo camponês - e no planejamento de uma nova política agrícola que levava em conta as novas relações entre o sistema econômico, a agricultura e o Estado. Esse movimento profissional camponês compreendia o quadro político, dentro do qual eram reguladas as relações entre os camponeses e o Estado.

Todavia, a oposição dos comportamentos políticos no campo da representação dos agricultores não era somente um reflexo das divergências ideológicas. Esses conflitos estavam relacionados ao lugar das diferentes camadas sociais dos camponeses no interior da organização da produção. As revoluções técnica e econômica que ocorreram no setor rural a partir de meados dos anos 40 provocaram resultados que abalaram definitivamente o mito da unidade. $\mathrm{O}$ mundo camponês era, na verdade, formado por produtores com situações econômicas e sociais heterogêneas.

As transformações da estrutura social da França camponesa modificaram os dados da vida política. Antes, a maioria dos camponeses tinha um comportamento conservador ao longo da história política do país. Posteriormente, parte dos 
pequenos camponeses passou a apoiar as forças da esquerda, embora poucos acreditassem na possibilidade de ter um papel ativo com a chegada de uma nova sociedade.

Ao mesmo tempo em que o sistema econômico exigia a eliminação de grande parte desses camponeses, considerados ineficientes, o sistema político necessitava, em algum sentido, garantir a existência dessa camada de pequenos produtores independentes:

Mais, à plus longue échéance, le nombre des paysans s'effritant encore, leur poids dans la vie politique tendra à devenir marginal. Ainsi, c'est au moment où, au terme d'une longue histoire, ils réussissent enfin à dégager leurs propres élites capables de défendre leurs intérêts propres, qu'ils se trouvent de plus en plus réduits au rang de force additionnelle (GERVAIS, JOLLIVET e TAVERNIER, 1976, p. 630).

Essa contradição foi percebida no meio rural a partir do início dos anos 60, gerando os antagonismos no interior do movimento profissional e justificando o nascimento de novas correntes sindicais, mas sem ainda provocar uma mudança importante nas atitudes políticas e no comportamento eleitoral dos camponeses. Enfim, nesse contexto de absorção rápida da agricultura pelo capitalismo, foi preciso eliminar o discurso da unidade camponesa para permitir que diferentes agricultores encontrassem o seu lugar dentro do sistema econômico.

O espaço político camponês francês foi discutido na obra dirigida por Yves Tavernier, Michel Gervais e Claude Servolin, L'univers politique des paysans dans la France contemporaine, produzida a partir de um colóquio realizado em 1970. Esse debate foi o resultado de uma análise das transformações das estruturas agrícolas, com a redução do número de explorações e de trabalhadores, mas, ao mesmo tempo, o aumento da produção e a absorção do setor agrícola pelo modo de produção capitalista; ou seja, a desordem provocada na sociedade camponesa tradicional pelas revoluções técnica e econômica na agricultura. As mudanças econômicas e sociais do mundo agrícola transformaram as condições de trabalho e os comportamentos sociais dos camponeses. A questão proposta pelos autores era em que medida essas mudanças econômicas influenciaram o comportamento político desses camponeses.

A agricultura francesa, a partir de 1955, alcançou seu melhor resultado do pós-guerra, tornando-se uma importante nação exportadora. Mas foi no início dos anos 70 que houve significativa mudança no ramo, quando as indústrias agrícolas e alimentares passaram a ser o seu principal mercado consumidor. O crescimento da produção agrícola também foi acompanhado por uma redução da participação do setor no sistema produtivo global. Um dos efeitos desse reordenamento do sistema produtivo foi a diminuição da população agrícola: "Ce réaménagement interne de l'appareil productif a provoqué de profonds bouleversements dans la distribution de la force de travail engagée dans la production 
et ces bouleversements ont affecté en premier lieu la population vivant de l'agriculture" (TAVERNIER, GERVAIS e SERVOLIN, 1972, p. 11).

Assim, o bom êxito do setor foi alcançado com a utilização dos recursos científicos e técnicos, produzindo um aumento na produtividade do trabalho e nos rendimentos por hectare. Essas transformações no processo de produção foram chamadas pelos economistas rurais de "industrialização da agricultura". O papel do Estado também mereceu destaque na orientação da produção e das estruturas de produção, ou seja, o destino dos agricultores estava intimamente ligado às políticas agrícolas seguidas.

Mesmo com a sua integração cada vez maior à economia global, não foi possível identificar uma unidade no mundo camponês. Existiam várias categorias de agricultores: o capitalista, o artesão que procurava o crescimento econômico e o pequeno e médio, submetidos à evolução técnica e que tentavam conservar a sua função de produtores. Em relação ao aspecto do conjunto dos camponeses enquanto um movimento social, afirmou-se que:

La "paysannerie" n'existe pas in abstracto comme force social et politique, elle est telle que son expérience syndicale et politique historique l'a façonnée; c'est au travers de cette expérience qu'elle a pris un certain visage, une certaine forme, et ceci pas seulement pour les autres forces sociales qui comptent dans la vie politique, et qui doivent compter avec elle, mais aussi pour elle-même (TAVERNIER, GERVAIS e SERVOLIN, 1972, p. 81).

O eleitorado camponês, num sentido amplo, era consideradoimportante para os partidos políticos. Todavia, a agricultura não era um campo independente com suas próprias leis de organização e de desenvolvimento. Assim, os programas agrícolas eram formulados segundo as lógicas políticas e econômicas globais. A falta de uma unidade no mundo camponês levou à reflexão sobre a natureza das relações políticas e ideológicas dos diferentes grupos de produtores rurais, no espaço das conexões estabelecidas pelo modo de produção capitalista que dominava a formação social do país.

\subsection{Crise, transformação e identidade social}

Em Le bal des célibataires, Pierre Bourdieu analisou, entre os anos 60 e 70, a crise da sociedade camponesa francesa através do estudo do celibato dos filhos mais velhos. A partir da descrição desse fenômeno, o autor conseguiu apreender as transformações pelas quais passou o mundo rural francês desde meados do último século.

No passado, o casamento aparecia como forma de defesa da continuidade da exploração agrícola. Tinha o caráter de uma transação econômica que reafirmava uma hierarquia social e a posição de cada família dentro dessa hierarquia, assegurando a manutenção da família e a integridade do seu patrimônio. $\mathrm{O}$ herdeiro era, preferencialmente, o primeiro homem a nascer, pois isso permitia 
a sucessão do nome da família. Além disso, o homem era considerado mais capaz para dirigir a atividade agrícola. As mulheres apenas seriam herdeiras quando não existisse um homem entre os filhos ou quando este partisse do meio rural. O casamento de uma herdeira com um filho mais jovem de outra família também possibilitava a garantia do patrimônio. Os herdeiros homens ou mulheres cumpriam a função de permanecer na atividade agrícola, sendo excluídos desse direito quando se afastavam da terra. Os celibatários, nesse contexto, eram os filhos mais jovens, e essa situação era considerada normal na lógica de proteção do patrimônio, de garantia e de perpetuação da hierarquia social. Era o sacrifício do indivíduo em benefício da coletividade.

No momento da pesquisa realizada pelo autor, no entanto, outra realidade foi percebida, ou seja, o celibato entre os proprietários de terras aparecia como a manifestação da crise que afetava a ordem social: "Alors que dans l'ancienne societé, le célibat était étroitement lié à la situation de l'individu dans la hiérarchie sociale, reflet elle-même de la répartition de la propriété fonciére, il apparaît aujourd'hui comme lié, avant tout, à la distribution dans l'espace géographique" (BOURDIEU, 2002, p. 56). Quer dizer,

[...] les chances au mariage sont moins étroitement liées à la situation socioéconomique qu'autrefois. Le privilège du propriétaire et de l'aîné est menacé. [...] Mais l'essentiel est que l'opposition entre les aînés d'une part, les cadets, les ouvriers et les domestiques d'autre part, se trouve reléguée à l'arrière-plan, sans être abolie, par l'opposition entre le citadin du bourg et le paysan des hameaux (BOURDIEU, 2002, p. 59).

Esse fenômeno revelava uma mudança no sistema de relações matrimoniais. A causa podia ser identificada no processo inflacionário após a Primeira Guerra Mundial e no seu efeito sobre o valor das propriedades e, consequentemente, dos dotes. A dependência das relações matrimoniais em consideração ao aspecto econômico mudou de forma: a posição na hierarquia social não era mais definida pelo patrimônio, mas pelo status social e pelo estilo de vida. Esse abalo na base econômica foi somado a uma mudança nos valores: a autoridade dos mais velhos foi enfraquecida por razões econômicas e pela influência da educação e de novos paradigmas. Enfim, "[...] la jeune génération ne comprend plus les modèles culturels anciens. À un système d'échanges matrimoniaux dominé par la règle collective, a fait place un système régi par la logique de la compétition individuelle. Dans ce contexte, le paysan des hameaux est tout spécialement désarmé" (BOURDIEU, 2002, p. 65). A desordem das relações matrimoniais poderia ser descrita da seguinte forma:

Ce que l'on observe en effet, ce n'est pas la désagrégation d'un système de modèles de comportement que viendraient remplacer de simples règles statistiques mais une véritable restructuration. Un système nouveau, fondé sur l'opposition entre villageois et le paysan des hameaux, tend à se substituer au système ancien 
fondé sur les oppositions entre l'aîné et le cadet d'une part, entre le grand et le petit propriétaire (ou le non-propriétaire) d'autre part. Considéré isolément, le système des échanges matrinoniaux des paysans des hameaux paraît porter en lui-même sa propre négation, peut-être parce qu'il continue à fonctionner en tant que système doté de règles propres, celles d'un autre temps, alors qu'il est pris dans un système structuré selon d'autres principes. Ne serait-ce pas précisément parce qu'il persiste à constituer un système, que ce système est auto-destructif? (BOURDIEU, 2002, p. 75).

A oposição entre os habitantes dos vilarejos (villageios) e os camponeses que moravam afastados desses vilarejos (paysans des hameaux), ou seja, entre os citadinos e os camponeses nasceu no interior da própria comunidade:

1. o tamanho das famílias nas cidades era menor, atraindo as jovens que preferiam casar dentro dessas famílias, visto que a grande família exercia controle e pressão maiores sobre as mulheres da nova geração;

2. a relação entre local de nascimento e de moradia era muito menor no bourg, ao contrário dos hameaux, conferindo um caráter mais diversificado para a primeira população e, consequentemente, uma maior abertura para o mundo exterior; e

3. a comunicação, que era realizada principalmente através do dialeto, passou a ser conduzida pelo francês, proporcionando uma relação maior com o mundo urbano (o dialeto era considerado uma língua inferior e vulgar pelos habitantes da cidade, ao contrário dos camponeses, que utilizavam-no como forma de expressão espontânea e relacionada com as preocupações do cotidiano).

A reestruturação do sistema de relações matrimoniais a partir da oposição entre obourg e os hameaux foi percebida como uma manifestação da transformação global da sociedade. O camponês estava numa posição desfavorável nessa competição. Houve a separação entre a sociedade masculina e a sociedade feminina, o desaparecimento dos intermediários e a flexibilização das relações sociais tradicionais. Assim, os bailes eram uma ocasião de encontro socialmente aprovado, mas também um local de tensões e de conflitos.

A sociedade apresentava uma abertura cada vez maior: de um lado, os valores rurais e, de outro, a influência crescente dos valores do mundo urbano. Isso acabou estimulando um êxodo rural mais significativo por parte das mulheres, pois estas se sentiam menos envolvidas com a tradição e com a atividade agrícola. Além disso, tinham mais facilidade em se adaptar ao ambiente citadino, em razão do seu nível de instrução. Assim, as mulheres se mostravam mais aptas que os homens para adotar o comportamento cosmopolita. A penetração das mulheres no modelo cultural urbano resultou num padrão de julgamento (aparência) que eliminava as chances de matrimônio para os camponeses, mesmo para aqueles agricultores dinâmicos, que utilizavam métodos modernos de produção - consi- 
derando que a aparência, os gestos e as atitudes de alguém são os primeiros aspectos percebidos por outras pessoas. Esse conjunto de características marcava imediatamente os camponeses que habitavam longe do vilarejo.

Os camponeses interiorizavam essa imagem, que era formada por outros e que era diferente da imagem dos citadinos, provocando uma atitude introvertida. Enfim, "Le célibat des hommes est vécu par tous comme l'indice de la crise mortelle d'une société incapable de perpétuer le lignage, bref, incapable de sauvegarder les fondements mêmes de son ordre, en même temps que de faire place à l'adaptation novatrice" (BOURDIEU, 2002, p. 126). O mercado matrimonial era uma oportunidade de percepção das transformações dos valores e da crise da ordem camponesa. Nos bailes era possível visualizar a passagem de uma lógica determinada pelo mercado local para outra definida pela economia de mercado.

A emigração e o celibato estavam estreitamente ligados e contribuíam para o desaparecimento dos pequenos empreendimentos agrícolas que fundamentavam a ordem rural em outra época. Como afirmou o autor,

[...] c'est l'effet des transformations globales de l'espace social et, plus précisément, de l'unification $d u$ marché de biens symboliques tel qu'il s'est exercé différentiellement sur les différents agents selon leur attachement objectif (maximum chez les aînés de grandes familles) et subjectif (c'est-à-dire inscrit dans les habitus et les hexis corporelles) au mode d'existence paysan d'autrefois (BOURDIEU, 2002, p. 219).

A unificação dos mercados de bens econômicos e simbólicos provocou o desaparecimento das condições de existência de valores camponeses capazes de resistir aos valores dominantes. No campo econômico, percebia-se uma dependência:

1. das máquinas, equipamentos e insumos químicos fornecidos pelo setor industrial e fundamentais para o aumento da produção e da produtividade;

2. das fontes de financiamento para implantar o processo de modernização da atividade, provocando o endividamento dos produtores;

3. das linhas de comercialização dos produtos, gerando, como consequência, uma demanda pré-determinada de bens que deveriam ser produzidos para a indústria alimentar;

4. da evolução dos preços (agrícolas e industriais); e

5. das políticas públicas.

Finalmente, através do ensino foi possível conhecer também a dominação simbólica do mundo citadino sobre os camponeses:

[...] l'ecole apparaît comme seule capable d'enseigner les aptitudes que le marché économique et le marché symbolique exigent avec une urgence sans cesse accrue, comme la manipulation de la langue française ou la maîtrise du calcul 
économique, la résistance jusque-là opposée à la scolarisation et aux valeurs scolaires s'évanouit. La soumission aux valeus de l'école renforce et accélère le reniement des valeurs traditionnelles qu'elle supose. Par là, l'école remplit as fonction d'instrument de domination symbolique, contribuant à la conquête d'un nouveau marché pour les produits symboliques citadins: lors même en effet qu'elle ne parvient pas à donner les moyens de s'approprier la culture dominante, elle peut au moins inculquer la reconnaissance de la légitimité de cette culture et de ceux qui détiennent les moyens de se l'approprier (BOURDIEU, 2002, p. 238).

Para Patrick Champagne, em L'héritage refusé, o mundo rural não se transformou unicamente no âmbito econômico: houve uma crise de identidade social. A sua investigação nas décadas de 70 e 80 mostrou que os motivos dessa redução gradativa da reprodução não estavam associados simplesmente à evolução técnica da produção, mas também aos aspectos socioculturais, isto é, à dominação simbólica do modo de vida urbano.

A crise de reprodução do campesinato francês, a partir dos anos 50, ocorreu em dois sentidos: a crise técnica, determinada pela ampliação da modernização da exploração agrícola, e a crise social, ocasionada pelo obstáculo da falta de sucessão, ou seja, uma crise interna ao grupo e revelada na dificuldade de encontrar um sucessor no interior da atividade produtiva.

Os estudos etnográficos realizados pelo autor apresentaram a desvalorização do modelo cultural camponês a partir da análise de práticas que até então simbolizavam o modo de vida urbano, como o período de férias: "[...] la diffusion d'une pratique qui symbolise aussi parfaitement, pour les paysans, le mode de vie 'urbain' et par laquelle ils peuvent exprimer leur 'modernité' e leur 'dynamisme', c'est-à-dire leur volonté d'accéder aux pratique des groupes auxquels ils tendent aujourd'hui à se comparer" (CHAMPAGNE, 2002, p. 20). Em outro momento, o autor afirmou que as festas dos vilarejos acabaram tornando-se um evento para o público exterior, passando uma imagem folclórica da condição camponesa. $\mathrm{O}$ processo de dominação simbólica é observado nessa explicação: "La crise des valeurs paysannes est sans doute principalement une crise de l'identité sociale, les paysans étant plus que jamais condamnés à recevoir de l'extérieur la définition de ce qu'ils doivent être, avec toutes les contradictions qu'une telle situation implique" (CHAMPAGNE, 2002, p. 46). Outro aspecto das transformações do mundo camponês referia-se ao momento da sucessão. Antes este era atrasado por meio do retardo da idade do casamento dos filhos, mas, agora, a questão era se existiria um sucessor, como afirmou:

Dans l'etat antérieur, l'âge au mariage des paysans tendait à s'ajuster à l'âge possible de reprise de l'exploitation des parents; la situation aujourd'hui inversée, l'âge de la succession devant s'ajuster à l'âge au mariage qui se fixe selon les lois de fonctionnement d'un marché matrimonial moins fortement et moins directement contrôlé par les familles. L'abaissement de l'âge au mariage des enfants des paysans et la réduction de l'écart d'âge entre les conjoints 
tiennent sans doute au fait que deux sur trois quittent aujourd'hui l'agriculture pour devenir salariés; mais aussi au fait que ces transformations ont entraîné un déplacement de l'âge socialement considéré comme 'normal' pour se marier, âge qui s'impose également à ceux qui restent sur l'exploitation (CHAMPAGNE, 2002, p. 140).

A capacidade de se reproduzir, no caso camponês, estava associada à possibilidade de existir um herdeiro social. As crises técnica e econômica do sistema de produção eram apenas parte do problema da sucessão familiar. A outra estava atrelada a uma crise interna da maioria das famílias agrícolas que não conseguiam encontrar entre os filhos um sucessor que aceitasse continuar a exploração. Além disso,

La position des paysans âgés s'est trouvée en outre affaiblie par un ensemble de mesures prises au début des années 1960, dans le cadre d'une nouvelle poltique agricole, qui visaient à accélérer la mise à la retraite des agriculteurs et s'appuyaient sur une idéologie moderniste dévalorisant tout ce qui était ancien, traditionnel ou vieux parce que perçu comme 'archaïde', 'routinier' et faisant obstacle au progrès (CHAMPAGNE, 2002, p. 141).

Ainda sobre esse aspecto, o autor destacou:

Cette législation n'a pas seulement eu pour conséquence d'abaisser l'âge de la succession, elle a également rendu impossibles les stratégies traditionnelles de transmission partielle de l'exploitation qui, dans cette région, permettaient aux paysans de se retirer progressivement sans coupure brutale. En outre, la politique agricole, en favorisant la diffusion d'une définition purement économique de la rentabilité et en poussant à accroître la taille des exploitations afin qu'elles soient 'rentables', a contribué à créer une très forte tension sur le marché foncier, chaque exploitant cherchant à s'agrandir. Il n'existe plus de petites fermes à louer sur lesquelles les paysans pourraient se retirer, et le prix du terrain, lorqu'il y en a à vendre, le met hors de leur portée.

[...]

Le patrimoine familial, s'il reste important pour l'héritier, ne lui suffit plus. Non seulement la possession de diplômes scolaires tend à devenir une condition au moins tacite pour se maintenir dans la profession (le Brevet d'études professionnelles agricoles est exigé, par exemple, pour l'obtention de certains prêts d'installation à taux bonifié), mais la taille de l'exploitation aujourd'hui socialement viable s'est accrue [...].

[...]

La modernisation des exploitations (modernisation du matériel agricole mais aussi de l'habitat) exige des investissements que les parents ne peuvent plus, comme auparavant, assumer seuls (CHAMPAGNE, 2002, p. 142-143). 
O modo de vida nas cidades, os atrativos salariais e a formação escolar eram fatores que reduziam o estímulo de se permanecer na atividade rural. Os jovens partiam para trabalhar como assalariados, obtendo vantagens como férias remuneradas e um maior conforto na moradia comparado ao modo de vida camponês. Além disso, o aumento do período de escolarização permitia um contato maior desses camponeses com jovens cuja realidade era diferente, como indicou o autor,

L'accès aujourd'huigénéralisédes fils de paysans au premier cycle del'enseignement secondaire a, en effet, transformé les relations de pouvoir à l'intérieur du groupe familial paysan en modifiant la division du travail d'éducation entre la famille et l'institution scolaire, en favorisant les comparaisons avec les enfants des autres classes sociales et en dotant les jeunes générations d'un capital scolaire (CHAMPAGNE, 2002, p. 136).

O desenvolvimento da escolarização e as facilidades do mercado de trabalho assalariado não eram suficientes, todavia, para explicar a saída de todos os filhos de uma família da atividade agrícola. O conjunto de políticas sociais direcionadas para os mais velhos foi crucial para libertar as novas gerações da obrigação moral de continuar a exploração familiar.

A especialização e a mecanização fizeram desaparecer não apenas alguns trabalhos agrícolas que se tornaram inúteis ou mesmo não rentáveis economicamente, mas também o calendário de festas religiosas que mobilizavam a comunidade. A razão disso foi a pluralidade de explorações e a própria individualização da produção. A desagregação da comunidade tradicional foi sentida mais profundamente pelos agricultores mais velhos.

Outro fenômeno foi a intensificação do êxodo rural, como indicado pelo autor:

[...] cette intensification de l'exode agricole est le produit d'une transformation profonde du mode de reproduction qui est corrélative du passage du monde rural comme ensemble de microsociétés locales dominées par l'activité agricole vers un espace plus large, qui s'intègre non seulement aux secteurs économiques non agricoles, mais aussi à un espace économique agricole différent. Cette modification substantielle s'exprime jusque dans les mots, puisque là où l'on parlait autrefois de 'succession familiale', on tend à parler aujourd'hui d'installation professionelle' (CHAMPAGNE, 2002, p. 201).

O modo de vida exterior ao mundo camponês foi imposto como dominante por meio da economia de mercado. As explicações para esses acontecimentos não se restringiam aos aspectos econômicos, estando ligadas a outras dimensões, como o capital cultural, isto é, os laços familiares e extrafamiliares. Essa dupla crise de reprodução - técnica/econômica e social/cultural - afetou o mundo camponês no último meio século. As justificativas excessivamente econômicas 
sobre as mudanças ocorridas no espaço rural foram confrontadas com a análise realizada pelo autor, já que a introdução das novas técnicas e o novo modo de vida da população rural provocaram uma nova identidade camponesa. Assim, além dos fatores econômicos, a crise de reprodução resultava também da necessidade de recursos sociais familiares e profissionais capazes de garantir a reprodução: "Si la crise de la reproduction de la paysannerie est ainsi indiscutablement liée aux facteurs économiques, c'est donc d'une façon indirecte. Le refus de succéder des enfants est, en premier lieu, refus du mode de vie des parents, la crise de la reproduction étant ici une crise de l'identité sociale" (CHAMPAGNE, 2002, p. 254-255).

Em outro estudo, De la succession familiale a l'installation professionnelle, Patrick Champagne e Sylvain Maresca analisaram o processo de reprodução social - os mecanismos de sucessão - no setor agrícola francês. O objetivo era compreender como se dava o problema da sucessão para os chefes de exploração que estavam próximos de se retirar da atividade. Segundo os autores, paralelamente ao processo de modernização da maioria das explorações, notava-se redução da população agrícola e grande recusa dos jovens pela atividade tradicional praticada por seus pais, ou melhor, uma recusa pelo modo de vida rural. As condições urbanas eram atraentes para os mais novos.

A sucessão é um negócio familiar, visto que o recrutamento dos produtores ruraiséassegurado pelas própriasfamílias. Esseauto-recrutamentoépropriedade específica do mundo agrícola. A sucessão depende das taxas de nupcialidade e de fecundidade, bem como do sexo dos filhos. O fator da escolarização, igualmente, conta muito, por ser gerador de transformações sociais no meio rural - a visão dos agricultores sobre eles mesmos está relacionada com outros grupos, e isso tem efeitos sobre as estratégias de sucessão e de reprodução. A capacidade de se produzir um sucessor é também o resultado da competência de se manter dentro desse espaço, que é, além de econômico, relacionado ao capital cultural - capital de formação e de informação. A questão se coloca, ainda, em termos de conflito de gerações, visto que, para se instalar, é preciso encontrar terras disponíveis, e isso ocorre, principalmente, quando os agricultores mais velhos se retiram da atividade. Enfim, a sucessão e a instalação não se referem apenas ao aspecto econômico - o economicamente viável -, já que não significa apenas a transmissão do patrimônio, mas também das condições sociais e econômicas de produção de um herdeiro.

Em relação aos representantes dos camponeses, Sylvain Maresca, no início dos anos 80, observou, em Les dirigeants paysans, que eles se diferenciavam dos demais camponeses porque possuíam propriedades econômicas, culturais e sociais diferenciadas. Eram os menos conformados com a realidade camponesa. Essas diferenças eram importantes para compreender o seu papel na liderança das organizações profissionais e os seus efeitos, além da forma como eram eleitos, como era produzida a imagem oficial e como era criado o seu discurso.

O reconhecimento das demais organizações agrícolas assegurava ao dirigente a sua legitimação pelo grupo dos camponeses. Esses representantes 
acabavam definindo, redefinindo e transformando a identidade social dos agricultores e a sua relação com outros grupos. Enfim, os dirigentes representavam uma imagem do conjunto de camponeses e impunham ao grupo essa imagem. Os porta-vozes dos agricultores apresentavam determinadas características, como boa situação financeira e utilização de mão de obra assalariada na exploração no caso da última, essencial para possibilitar a ausência frequente da atividade e a dedicação à vida pública. Além disso, a excelência profissional quanto à adoção de inovações, ao desempenho técnico ou econômico e ao comportamento inovador, e a relação com o conhecimento adquirido pela herança também eram aspectos considerados como capital diferenciado dos dirigentes, que lhes davam legitimidade para representar os demais camponeses. A formação escolar permitia uma capacidade maior de falar e de exprimir-se com facilidade e de compreender os problemas econômicos e sociais importantes na condução das negociações com representantes do poder público.

Nas palavras do autor: "Les représentants de la paysannerie possèdent généralement des propriétés économiques, culturelles et sociales peu répandues dans le milieu agricole, qui les distinguent du reste des paysans. Autrement dit, ceux qui ont pour charge de donner de la paysannerie la représentation dominante sont les moins conformes à la réalité dominante de la paysannerie" (MARESCA, 1983, p. 49). A representação profissional e sindical dos agricultores era essencial na definição e imposição de uma identidade camponesa:

Conduits par disposition et par contrainte à ne plus être que des agriculteurs à temps partiel, mis en disponibilité por la représentation des intérêts agricoles, et, por les plus importants d'entre eux, à n'être plus que des agriculteurs de pure forme, vivant parfois uniquement de la rémunération de leur activité publique, les dirigeants paysans nationaux fondent une grande partie de leur crédibilité sur l'identité officielle qu'ils parviennent à se donner grâce à un travail de présentation qui est constitutif de leur travail de représentation. La réussite de cette mise en scène, qui s'adresse à la paysannerie elle-même, aux autres groupes sociaux, aux milieux dirigeants nationaux, repose sur l'aptitude des représentants agricoles à se montrer sous des jours différents, à donner une représentation à sens multiples, également recevable par l'ensemble des demandeurs d'une représentation de la paysannerie (MARESCA, 1983, p. 197).

A certeza da representação que os dirigentes agrícolas davam ao conjunto de camponeses com a imposição de uma identidade do grupo era um fator que merecia consideração na mobilização dos agricultores, isto é,

L'identification aux représentants paysans qui impose de/à la paysannerie l'image d'un groupe professional composé de chefs d'entreprise conforte les fractions paysannes aptes à se conformer économiquement et socialement au modèle d'une agriculture d'entreprise, dans le même temps où les tendances de l'évolution économique les confirment dans leur position d'avenir. L'importance de plus 
en plus grande prise par les organisations agricoles et leur représentation de la paysannerie tient peut-être à l'évolution accélérée imposée au milieu agricole: dans ce changement permanent qui affecte les techniques de production, l'environnement économique et commercial, l'encardrement juridique de l'activité agricole, etc., le groupe paysan est probablement condamné pour survivre en tant que groupe social à produire (ou à subir) un travail continuel de redéfinition de son identité sociale et à s'en remettre à ses représentants, seuls en mesure de produire à son intention des prophéties sur son avenir dans lesquels se reconnaissent ceux de ses membres qui ont un avenir - de plus en plus représentatifs de ce que devient le groupe paysan (MARESCA, 1983, p. 222).

A legitimidade dos porta-vozes dos camponeses aumentava à medida que se tornava mais representativa do modelo social interpretado por eles. A nomeação desse grupo também era necessária para a estratégia de mobilização. Os termos "camponês" e "agricultor" correspondiam a origens diferentes: o primeiro remetia ao campo, ao interior, à unidade social herdada do grupo, às virtudes coletivas antigas, à resistência ao Estado e à mobilização de um grupo mal definido; e o segundo termo, à exploração agrícola, ao ambiente econômico, ao setor socioprofissional, aos indivíduos organizados, ao produto de uma evolução, à colaboração com o poder público, aos interesses individuais selecionados. Não eram termos sobrepostos, ou seja, a utilização de um ou de outro se referia ao objetivo do dirigente.

Os dois termos - e as realidades específicas de cada - não tinham o mesmo valor simbólico no interior das categorias dominantes de compreensão profissional. O agricultor representava o movimento, a profissão e o futuro, enquanto o camponês estava atrelado à permanência, à herança e ao passado. Entretanto, como afirmou o autor, "En appeler alternativement aux deux, grâce au sens inévitablement double du discours de ces dominants d'un groupe dominé que sont les porte-parole agricoles reconnus, c'est mobiliser l'ensemble de la paysannerie, les agriculteurs d'avenir comme les paysans menacés" (MARESCA, 1983, p. 226).

Ao mesmo tempo em que se comportavam como representantes dominantes do grupo de camponeses - com determinadas propriedades sociais -, os dirigentes assumiam uma postura de dominados entre os representantes dos demais grupos, pois representavam um grupo social dominado. No espaço de representação, os representantes do sindicalismo unitário apresentavam superioridade em relação às outras organizações do meio rural.

Ao longo do tempo, portanto, o grupo de camponeses passou por transformações e se constituiu numa entidade social a partir da existência de uma profissão agrícola. Isso se deu com a criação de instituições encarregadas em representá-los e com a imposição de uma definição da própria atividade agrícola. A unidade dos camponeses permitiu a sua relação com o poder público, mas somente devido à convicção da definição profissional com a qual foram conduzidos a se identificar. 


\subsection{Modernização e reconhecimento profissional da mulher na atividade agrícola}

Rose-Marie Lagrave, em Celles de la terre: agricultrice - l'invention politique d'un métier, organizou um estudo sobre o reconhecimento profissional da mulher na atividade agrícola. O processo de modernização rural foi objeto das políticas agrícolas após a Segunda Guerra, já que era necessário assegurar a independência alimentar do país, participar do grupo dos países exportadores, equilibrar a balança comercial e liberar mão de obra para o setor urbanoindustrial. O Estado teve o apoio da Jeunesse Agricole Catholique (JAC) e do Centre National des Jeunes Agriculteurs (CNJA) para conduzir sua política de reestruturação do processo produtivo.

É possível compreender como o modelo da agricultora - mãe, trabalhadora e militante - foi construído através da conjuntura econômica e social, a partir da análise dos jornais do ramo feminino da JAC (Jeunesse Agricole Catholique Féminine - JACF). As mulheres eram consideradas os agentes da modernidade e, ao mesmo tempo, sustentadoras dos valores da família agrícola. Essa análise expôs a complexidade da construção da identidade profissional da mulher no meio rural.

Desde meados dos anos 30, a JACF lutava contra o êxodo rural e pela dignidade no mundo camponês. A mulher tinha o objetivo de manter o homem no campo e de educar as futuras gerações. Na primeira metade dos anos 40, a mulher foi estimulada a participar da vida pública do vilarejo. Na segunda metade, os resultados da guerra promoveram o discurso da modernização agrícola e da adoção do modo de vida urbano, mas sem renunciar à qualidade da vida rural. Os anos 50 marcaram a passagem da relação "colaboradora" para a "associada", indicando um período de discussão sobre as condições de profissionalização das mulheres na agricultura.

O papel da mulher na atividade agrícola também foi registrado mediante estudo da revista Agri-Sept, identificando-se a transição de uma visão cristã da mulher e da família para uma concepção de uma agricultora moderna e competente, mas sem permitir que ela tivesse consciência objetiva de sua situação, ou seja, a sua profissionalização. As mulheres eram os agentes ativos da modernização no campo, da abertura para o mundo exterior e do rompimento com a tradição. A família rural, assim, passou a se definir pela sua relação com o exterior: o mundo urbano.

Quanto ao campo sindical, as mulheres interiorizavam o discurso dos sindicatos sobre a atividade do casal e a exploração familiar. O interesse era a famíliaexploração. Elas lutavam pela causa das associações antes da sua própria luta pela situação profissional. Tinham consciência da injustiça da sua condição, mas encontravam obstáculos na oposição sindical e política. E, quando participavam ativamente da vida política, deparavam-se com um paradoxo: defendiam e representavam uma profissão sem ter a sua própria situação profissional definida. 
Essas dirigentes eram oriundas dos camponeses médios. Apresentavam situação econômica favorável, derivada da condição dos pais ou do casamento com agricultor. Não praticavam uma agricultura à distância, ou seja, participavam ativamente da exploração. Associavam o trabalho sindical com a atividade de mãe e de esposa. Enfim, para as dirigentes, o reconhecimento era obtido pelo seu sucesso no campo familiar, profissional e político: "Le regard de la famille, du voisinage, des autres agricultrices constitue un contrôle social dont l'efficacité est au principe de leur reconnaissance par le milieu" (LAGRAVE, 1987, p. 173). Todavia, ocupavam apenas as posições subalternas na hierarquia sindical. A divisão sexual do trabalho não ocorria apenas dentro da atividade, mas também no espaço de representação política. A participação política das agricultoras aparecia como uma estratégia para compensar a ausência do seu reconhecimento profissional, e as manifestações públicas constituíam um cenário favorável para a representação da profissão. Entretanto, mesmo as reivindicações estavam inseridas dentro dessa divisão sexual do trabalho.

\section{Conclusões}

O exame desta produção do conhecimento revelou múltiplos olhares de pesquisadores, que permitiram a construção de diferentes categorias na análise da modernização agrícola francesa. Destaca-se o fato de o mundo rural não ter se transformado unicamente no âmbito econômico: houve, ainda, uma crise de identidade política e social no campo. Os motivos dessa crise não estavam associados simplesmente a transformações econômicas ligadas à produção, mas também aos aspectos socioculturais.

A crise de reprodução da lógica de relações que definiam o meio rural ocorreu em dois sentidos a partir dos anos 50: a crise técnica, determinada pela ampliação da modernização da exploração agropecuária, e a crise social e política, ocasionada pelo obstáculo da falta de sucessão, ou seja, uma crise interna ao grupo revelada na dificuldade de encontrar formas de manutenção das relações existentes no interior da atividade produtiva.

No caso brasileiro, a produção acadêmica tem privilegiado as análises que revelam o setor rural interno ao longo de sua transformação, apoiado pela presença do Estado rumo ao seu desenvolvimento. Esse apoio se deu por meio de políticas de financiamento e de incentivos ao processo de modernização. Ao longo da formação econômica do Brasil, o Estado conduziu o setor rural de acordo com os interesses econômicos e políticos vigentes não apenas no País, mas também na economia mundial. Além disso, observou-se uma nova relação política, que englobava as novas articulações entre o setor rural, o sistema econômico e o Estado.

Nessa direção, pesquisas como a de Kageyama e Silva (1996) procuraram explicar o processo de transformação da agricultura. Para os autores, em primeiro 
lugar, houve a modernização da agricultura por meio da mudança na base técnica de produção, com a introdução de máquinas, implementos, defensivos, fertilizantes, novas variedades de culturas etc. ("insumos modernos"); em segundo lugar, ocorreu a industrialização da agricultura quando esta passou a ser considerada um ramo de produção semelhante à indústria, comprando insumos e vendendo matérias-primas; e, por último, a constituição dos Complexos Agroindustriais, que representam um conjunto de atividades com fortes relações de compra e venda entre si e pouco relacionadas com as demais atividades. Silva (1996, p. 30) afirmou que a modernização do setor agrícola deve ser entendida como um "[...] processo genérico de crescente integração da agricultura no sistema capitalista industrial, especialmente por meio de mudanças tecnológicas e de ruptura das relações de produção arcaicas e do domínio do capital comercial". O aprofundamento das relações sociais capitalistas de produção, identificado na transformação das formas de trabalho realizadas no meio rural, também é um aspecto marcante do processo de modernização, além da mudança na base técnica de produção. As transformações não foram restritas aos aspectos técnicos. A própria força de trabalho humano foi substituída pelo uso da força mecânica com a introdução do progresso técnico, possibilitando o aumento da produção e da produtividade. Enfim, no âmbito da produção agrícola, de acordo com o autor, as principais mudanças ao longo dos anos 30, 40 e 50 foram a intensificação da produção e a diversificação dos produtos, garantidas pela utilização de máquinas, equipamentos e insumos químicos. No campo da circulação, a distribuição da produção pelo interior do mercado nacional foi possibilitada pelo desenvolvimento da rede de transportes. A modernização agrícola esteve atrelada ao exterior até os anos 60, já que os insumos utilizados tinham origem fora do mercado brasileiro.

Outras pesquisas, como a de Aguiar (1986), investigaram os principais resultados do processo de modernização agrícola. $\mathrm{O}$ autor analisou a especialização da agricultura em alguns produtos em cada região brasileira, gerando dificuldades para a pequena propriedade rural (eliminou as culturas de subsistência) e estimulando as médias e grandes propriedades (estabeleceu as relações capitalistas de produção). Notou-se modernização desigual no território nacional (destaque para as regiões Sul, Sudeste e Centro-Oeste), além de concentração fundiária e proletarização do trabalhador rural.

O tema da formulação de políticas para o setor, abordado no estudo de Massuquetti (1998), também esteve na pauta de investigação dos cientistas sociais. A autora afirmou que os principais mecanismos adotados pelo governo federal foram a pesquisa, o fomento, o crédito agrícola e a política de preços mínimos. O objetivo principal era promover o processo de modernização da agricultura brasileira. A forma encontrada para viabilizar a integração da agricultura a este processo foi o incentivo à utilização dos "insumos modernos" por meio do fornecimento de recursos financeiros. Estes eram repassados 
aos produtores com taxas de juros favorecidas e prazos maiores. O marco de constituição dessa nova fase foi a criação do Sistema Nacional de Crédito Rural (SNCR) em 1965.

A partir desses estudos com foco no Brasil, é possível indicar que as mudanças na atividade agropecuária estiveram relacionadas às transformações da economia no País. Mesmo com diferenças entre as estruturas de produção rural e industrial, as pressões econômicas, sociais e políticas foram as mesmas. Significa dizer que a evolução dos setores rural e industrial estava submetida à necessidade do desenvolvimento do capitalismo, levando em consideração as particularidades de cada ramo. Nesse novo cenário econômico, o setor rural passou a desempenhar outro papel a partir das modificações estruturais da economia. O panorama era constituído, assim, por uma economia dominada por uma estrutura que se transformou e cujo centro passou progressivamente para as atividades econômicas mais lucrativas. A modernização do setor rural e os incentivos ao aumento da produção estavam inseridos dentro do próprio processo de modernização da economia brasileira. A questão agrária, nesse contexto, estava inserida numa estratégia de desenvolvimento econômico, e a desapropriação de terras era efetuada apenas nos casos de tensões sociais, ou seja, quando o objeto final era o interesse nacional. Este, por exemplo, era o teor da reforma agrária proposta naquele período pelo Estado.

Este estudo atingiu seu objetivo, contribuindo para a construção de percepções acerca do processo de modernização agrícola a partir de outros campos - que não exclusivamente o econômico -, como o político e o cultural. As problemáticas que devem orientar pesquisas sobre o tema no Brasil, portanto, estariam relacionadas não apenas à análise das transformações econômicas provocadas pela introdução de inovações, mas também à constituição da identidade social e política dos trabalhadores do meio rural, a partir de dimensões políticas e culturais.

\section{Referências Bibliográficas}

AGUIAR, R. C. Abrindo o pacote tecnológico: Estado e pesquisa agropecuária no Brasil. São Paulo: Polis, 1986.

ALLAIRE, G.; BOYER, R. (édit.). La grande transformation de l'agriculture: lectures conventionnalistes et régulationnistes. Paris: INRA/Economica, 1995.

BOURDIEU, P. Le bal des célibataires: crise de la société paysanne en Béarn. Paris: Éditions du Seuil, 2002.

CHAMPAGNE, P. L'héritage refusé: la crise de la reproduction sociale de la paysannerie française 1950-2000. Paris: Éditions du Seuil, 2002.

CHAMPAGNE, P.; MARESCA, S. De la succession familiale a l'installation professionnelle. Paris/Dijon: INRA/ENSSAA, 1986. 2 vols. 
GERVAIS, M.; JOLLIVET, M.; TAVERNIER, Y. La fin de la France paysanne: de 1914 à nos jours. Paris: Éditions du Seuil, 1976. (Histoire de la France Rurale. Tome 4).

KAGEYAMA, A.;SILVA,J.G. da. Do complexo rural aos complexos agroindustriais. In: SILVA, J. G. da. A nova dinâmica da agricultura brasileira. Campinas: UNICAMPIE, 1996.

LAGRAVE, R-M. Celles de la terre: agricultrice - l'invention politique d'un métier. Paris: Éditions de l'École des Hautes Études en Sciences Sociales, 1987.

MARESCA, S. Les dirigeants paysans. Paris: Les Éditions de Minuit, 1983.

MASSUQUETTI, A. A mudança no padrão de financiamento da agricultura brasileira no período 1965-97. 1998. Dissertação (Mestrado em Economia Rural) - Faculdade de Ciências Econômicas, Universidade Federal do Rio Grande do Sul, Porto Alegre.

MENDRAS, H. La fin des paysans. Arles: Babel, 1992.

SILVA, J. G. da. A nova dinâmica da agricultura brasileira. Campinas: UNICAMP-IE, 1996. 1981. cap. 1.

Progresso técnico e relações de trabalho na agricultura. São Paulo: HUCITEC,

TAVERNIER, Y.; GERVAIS, M.; SERVOLIN, C. (org.). L'univers politique des paysans dans la France contemporaine. Paris: Armand Colin/Fondation Nationale des Sciences Politiques, 1972. 
